\title{
"A PALAVRA É O MEU DOMÍNIO SOBRE O MUNDO": CIRCULAÇÃO E RECEPÇÃO DA OBRA DE CLARICE LISPECTOR EM PORTUGAL
}

Natália Guerellus ${ }^{1}$

Resumo: O presente artigo tem uma dupla ambição: propor um panorama da bibliografia voltada para a circulação e recepção da obra da escritora brasileira Clarice Lispector (1920-1977) no âmbito internacional; e estudar estes mesmos fenômenos em Portugal, onde a questão da tradução não tem a mesma importância que em outros países. Neste sentido, a análise se baseia em dois conjuntos de documentos diferentes, além da bibliografia especializada: primeiramente, lanço um olhar sobre as publicações da obra de Clarice Lispector em Portugal a fim de identificar seus canais de circulação; num segundo momento, volto-me para as leituras de Lispector em Portugal, dando especial atenção ao papel dos mediadores. O trabalho pretende, assim, contribuir de maneira original à história transatlântica dos escritos a partir do exemplo do Brasil, visto por um outro país lusófono.

Palavras-chave: Estudos Transatlânticos. Literatura brasileira. Portugal. Clarice Lispector.

\section{WORDS ARE MY DOMAIN ON THE WORLD": CIRCULATION AND RECEPTION OF CLARICE LISPECTOR'S WORK IN PORTUGAL}

\begin{abstract}
This article has a twofold ambition: propose a panorama of the bibliography devoted to the circulation and reception of the Brazilian writer Clarice Lispector (1920-1977) on an international scale; study these two aspects in Portugal, where the question of translation is not the same as in other countries. In this sense, the analysis is based on two different categories of documents in addition to the specialized bibliography: first, I look at publications of Clarice Lispector's work in Portugal in order to identify its channels of circulation; secondly, I turn to the reception of Lispector's works in Portugal, paying special attention to mediators. The paper thus aims at being an original contribution to the transatlantic history of writings based on the example of Brazil, as seen from another Portuguese-speaking country.
\end{abstract}

Keywords: Transatlantic Studies. Brazilian Literature. Portugal. Clarice Lispector.

\section{LA PALABRA ES MI DOMINIO SOBRE EL MUNDO": CIRCULACIÓN Y RECEPCIÓN DE LA OBRA DE CLARICE LISPECTOR EN PORTUGAL}

Resumen: Este artículo tiene una doble ambición: proponer un panorama de la bibliografía dedicada a la circulación y recepción de la escritora brasileña Clarice Lispector (1920-1977) a escala internacional; estudiar estos dos aspectos en Portugal, donde la cuestión de la traducción no es la misma que en otros países. En este sentido, el análisis se basa en dos categorías diferentes de documentos, además de la bibliografía especializada: en primer lugar, examino las publicaciones de la obra de Clarice Lispector en Portugal para identificar sus canales de circulación; en segundo lugar, me ocupo de la recepción de las obras de Lispector en Portugal, prestando especial atención a los mediadores. El artículo pretende así ser una contribución

\footnotetext{
${ }^{1}$ É professora adjunta no departamento de Estudos Lusófonos da Université Jean Moulin Lyon 3. Foi pesquisadora Capes/Print Jovens Talentos na Universidade Federal do Rio Grande do Sul, Ingénieure de Recherche e Attachée Temporaire dEnseignement et de Recherche na Université Jean Moulin, Lectrice na Université Paris Nanterre e professora assistente no Centro Universitário Campos de Andrade, Brasil. É doutora em História Contemporânea pela Universidade Federal Fluminense (UFF) com apoio da Coordenação de Aperfeiçoamento de Pessoal de Nível Superior (CAPES).
} 
original a la historia transatlántica de la escritura a partir del ejemplo de Brasil, visto desde otro país de habla portuguesa.

Palabras clave: Estudios transatlánticos. Literatura brasileña. Portugal. Clarice Lispector.

"Eu nasci para escrever, a palavra é meu domínio sobre o mundo"

Clarice Lispector $(1968,02)$

Clarice Lispector (1920-1977) é provavelmente a escritora brasileira mais conhecida no Brasil e no estrangeiro" ${ }^{2}$ Seu primeiro romance, "Perto do coração selvagem", foi publicado em dezembro de 1943, mas, só nos anos 60, a universidade, para além do estreito círculo da crítica literária especializada, se ateve à importância da sua obra. Já o interesse dos pesquisadores e pesquisadoras pela circulação e recepção da obra de Lispector a nível internacional é recente, com os primeiros estudos tendo sido publicados nos anos $90^{3}$.

Investigações realizadas até agora têm algumas características em comum: analisa-se em particular o estudo da circulação e recepção do trabalho de Lispector através da análise das traduções, através de métodos da tradutologia, e com base na reconstrução da cronologia dos livros traduzidos e da lista das editoras de Lispector no exterior.

As pesquisas também analisam contratos de publicação e constituem um panorama de tradutores e professores universitários brasileiros que estudaram Clarice Lispector fora do Brasil. Vale a pena notar que, embora seus livros sejam comercializados por diferentes editoras, os direitos de publicação foram frequentemente adquiridos por uma determinada casa editorial. Este foi o caso na Espanha com a editora Siruela, na França com a Éditions des Femmes, na Alemanha com a Suhrkamp e em Portugal com a Relógio D'Água.

Finalmente, os estudos dedicados à obra de Lispector no exterior centraram-se principalmente nos espaços europeu e norte-americano, com foco em traduções para as línguas latinas, para o inglês e o alemão. Ao fazê-lo, estes estudos permitiram uma melhor

\footnotetext{
${ }^{2}$ Gostaria de expressar a minha gratidão a Abel Barros Baptista, Clara Rowland, Michel Riaudel e a Nuno Medeiros pelas trocas que tivemos durante a elaboração desta investigação, e a Mélanie Toulhoat e Sébastien Rozeaux pelas suas correções e comentários sempre pertinentes sobre a minha contribuição.

${ }^{3}$ A França foi o primeiro país europeu a publicar uma tradução da obra de Lispector em 1952, e um dos primeiros a traduzi-la quase na sua totalidade. Para uma visão geral da circulação internacional da Lispector, ver: ARF, 2015; CARRERA, 1999; DE CASTRO, 2016; HANES \& GUERINI, 2016; MIRROIR, 2016; PEREIRA, 1995; DA SILVA, 2015; CHEREM, 2013.
} 
compreensão da difusão internacional da obra de Lispector, enquanto a grande maioria da literatura brasileira nunca foi publicada fora das fronteiras do país.

Três fatores principais podem explicar esta especificidade: o chamado boom da literatura latino-americana entre os anos 60 e 80, apesar de terem predominado traduções de autores homens e de língua espanhola, abriu uma nova perspectiva à literatura brasileira de vanguarda na Europa e nas Américas. No Brasil, Lispector e Guimarães Rosa (1908-1967) são os nomes mais frequentemente associados a esta categoria ${ }^{4}$.

Uma segunda explicação frequentemente evocada nestas pesquisas aponta para o importante papel da crítica literária feminista na difusão de Clarice Lispector em francês, inglês e alemão. De fato, o feminismo francês estabeleceu uma relação original com a obra da autora brasileira, especialmente através do trabalho da intelectual franco-argelina Hélène Cixous, que publica artigos e livros sobre Lispector a partir de $1978^{5}$.

Já na Espanha, a situação é diferente. De acordo com Lucilene Machado Garcia Arf, o nome de Lispector circulou no início dos anos 70 através de traduções latinoamericanas dos seus livros da Argentina, Chile e Venezuela ${ }^{6}$. Tais circulações conduziram a uma primeira difusão internacional do seu trabalho, embora ainda modesta, ligada mais à sua identidade latino-americana (ARF, 2015, p. 19). Somente depois a interpretação feminista chegaria no país.

Finalmente, os críticos literários estrangeiros, homens e mulheres, especializados e os(as) tradutores(as) de Lispector optaram por realçar a originalidade do estilo da autora em relação à literatura regionalista brasileira. Esta tendência literária, representada por traduções das obras de José Lins do Rêgo (1901-1957), Jorge Amado (1912-2001), Graciliano Ramos (1892-1953) ou Rachel de Queiroz (1910-2003), foi divulgada por estudos literários brasilianistas no exterior antes dos anos 70, mantendo relação com uma

\footnotetext{
${ }^{4}$ Clarice Lispector, inclusive, participou no XI Congresso do Instituto Internacional de Literatura IberoAmericana na Universidade do Texas em 1963, durante o qual proferiu uma palestra sobre literatura de vanguarda no Brasil.

${ }^{5}$ Cixous contribuiu grandemente para a divulgação do trabalho de Lispector nos países em que seus próprios trabalhos foram traduzidos e nos quais teve a oportunidade de participar como professora em eventos, palestras e conferências. Ver entrevista com Hélène Cixous, "Derrubamos o regime, mas não tomamos o poder," RFI France [online] publicada em 24 de Abril de 2018. Disponível em: http://br.rfi.fr/franca/20180419-entrevista-helene-cixous-maio-de-1968. Acesso em: 30 abr. 2018. Ver também: CIXOUS, 1979. Considerações críticas importantes as estas posições podem ser encontradas em: CARRERA, 1999; HELENA, 2010.

${ }^{6}$ Sobre as traduções de autores brasileiros na Argentina, ver em particular: SORÁ, 2003.
} 
representação folclórica do Brasil. O trabalho de Lispector teria, assim, tornado possível emancipar-se de uma literatura brasileira orientada para as questões nacionais.

Gostaria de acrescentar uma quarta razão para o sucesso mais recente de Lispector, em comparação à publicação de outros autores e autoras brasileiros no exterior. A internacionalização de sua obra nos últimos vinte anos deve-se também ao projeto editorial da editora Rocco no Brasil, às políticas de divulgação do governo brasileiro e à publicação da sua biografia pelo escritor americano Benjamin Moser. Best-seller no Brasil quando foi publicado em português em 2009, esta publicação está atualmente presente nas estratégias com que a obra de Lispector circula internacionalmente.

Ao construir este panorama da circulação de Lispector em línguas estrangeiras, reparei na escassez de estudos sobre os vários países de expressão portuguesa ${ }^{7}$. Daí o desejo de preencher esta lacuna estudando a circulação e recepção do trabalho de Clarice Lispector em Portugal, um país com relações originais, como se sabe, com o Brasil ${ }^{8}$. O trabalho, do ponto de vista das semelhanças e especificidades desta recepção em Portugal, está, assim, relacionado com as pesquisas realizadas em outros mercados editoriais, na Europa e na América do Norte.

Para isto, vou identificar, primeiramente, as circulações da obra de Lispector em Portugal, e em seguida investigar a recepção pelos leitores portugueses, a fim de destacar alguns mediadores específicos. Ao fazê-lo, concentrar-me-ei na circulação transatlântica dos escritos, nas disputas dentro do mercado editorial lusófono, no ensino universitário da literatura brasileira em Portugal e nas releituras em Portugal da obra de uma autora brasileira cuja reputação se tornou, desde então, universal. Também me parece fundamental analisar o papel dos mediadores e dos contextos políticos de publicação dos livros nestes processos, numa perspectiva diacrônica. De fato, certas políticas estatais tiveram um impacto considerável na redefinição do mercado e do campo literário em língua portuguesa.

\section{A publicação de Clarice Lispector em Portugal}

Gostaria de salientar, desde o início, que o estudo de um escritor ou escritora brasileiro publicado em Portugal não nos permite ignorar a questão da "tradução". As

\footnotetext{
${ }^{7}$ Alguns estudos aproximaram-se do tema. Ver: DUMAS, 2005; FRIAS, 2004; SANCHEZ-ELEZ, 2015; FARIA, 2015.

${ }^{8}$ Para uma síntese recente em francês sobre este ponto, ver: ROZEAUX, 2019.
} 
variantes da língua portuguesa trouxeram frequentemente problemas a editores e autores em ambos os países ao longo do tempo ${ }^{9}$. Mas, para além das variações linguísticas, houve também disputas no interior do próprio sistema editorial lusófono.

O sociólogo português Nuno Medeiros descreve os anos 1930-1960, período das primeiras publicações de Clarice Lispector, como um período de "inversão dos processos de influência tipográfica" entre o Brasil e Portugal (MEDEIROS, 2018). As editoras portuguesas, habituadas a considerar o Brasil como o principal mercado consumidor dos seus livros, foram confrontadas com o notável crescimento do mercado editorial brasileiro, em um contexto de profundas mudanças econômicas e políticas em ambos os países. Em Portugal, o Estado Novo salazarista contribuiu com a precariedade do mercado editorial nacional ao praticar a censura e a repressão intelectual e política em grande escala. A escassez de financiamento público para os livros, a elevada taxa de analfabetismo e a manutenção de práticas artesanais na produção de livros foram obstáculos ao desenvolvimento do mercado português à época.

A circulação dos impressos entre os dois países era também difícil, apesar das tentativas de cooperação bilateral para relançar a velha ideia de uma "unidade ideológica luso-brasileira" ${ }^{10}$. Os problemas de conversão cambial devido à inflação galopante no Brasil tornaram ainda mais difícil a exportação de livros por via marítima, especialmente durante a Segunda Guerra Mundial ${ }^{11}$. O não pagamento pelo Banco do Brasil de somas devidas aos exportadores portugueses e as tensões entre os mercados editoriais ligadas à aquisição de direitos de tradução em língua portuguesa enfraqueceram ainda mais a circulação recíproca de material impresso.

Já o Brasil, aprovou o decreto 25.442 em 3 de setembro de 1948, que impedia a importação de obras de autores estrangeiros traduzidas ou publicadas em Portugal. Até a sua suspensão em 1956, este decreto beneficiou toda uma geração de escritores brasileiros

\footnotetext{
${ }^{9}$ Sobre a história específica das relações linguísticas entre os dois países, ver em particular: FARACO, 2016.

${ }^{10}$ Refiro-me aqui ao acordo cultural luso-brasileiro de 1941, entre o Estado Novo brasileiro e o Estado Novo salazarista, que se seguiu às convenções aprovadas em 1922. O acordo destinava-se a promover a divulgação de artistas e escritores brasileiros em Portugal, e vice-versa. Ver: HALLEWELL, 1985, p. 280281.

${ }^{11}$ Estas dificuldades levaram a uma reconfiguração das importações de livros estrangeiros para o Brasil, uma vez que o país se voltou mais para os países da América Latina, particularmente para a Argentina. Ver: HALLEWELL, 1985, p. 404.
} 
que foram contratados para a tradução, tais como Clarice Lispector, que traduziu mais de trinta livros do francês e do inglês para português desde $1941^{12}$.

"Perto do coração selvagem", o primeiro livro de Lispector publicado no Brasil em 1943 e vencedor do Prêmio Graça Aranha no ano seguinte, foi entusiasticamente recebido por parte da crítica literária brasileira ${ }^{13}$. No entanto, após o seu casamento com o diplomata Maury Gurgel Valente, Lispector permaneceu na Europa e nos Estados Unidos durante mais de quinze anos, o que contribuiu para o seu afastamento do campo literário brasileiro. No Brasil, Clarice Lispector também teve grande dificuldade em estabelecer e assinar contratos editoriais satisfatórios (HALLEWELL, 1985, p. 388). Já em Portugal, sua inovação estilística parece ter colidido com as expectativas literárias predominantes, marcadas pelo neorrealismo. Tudo isto ajuda na compreensão da ausência de edições portuguesas dos livros de Clarice Lispector antes de 1961, embora, segundo Jean-Claude Miroir (2016), a autora tenha sido sempre muito ativa na promoção da sua obra a nível internacional.

De fato, em agosto de 1944, pouco antes de encontrar-se com o marido na Itália, Lispector hospedou-se em Lisboa, onde conviveu com o diplomata e escritor brasileiro Rui Ribeiro Couto (1898-1963). A escritora pediu às suas irmãs no Brasil que enviassem cópias do seu livro (LISPECTOR, 2002, loc. 560) à poetisa portuguesa Natércia Freire (1920-2004), ao crítico literário João Gaspar Simões (1903-1987) e à escritora Maria Archer (1899-1982). Contudo, só em 1961 é que uma de suas obras seria publicada em Portugal, pela editora Livros do Brasil, propriedade do editor português Antônio Sousa Pinto, personagem singular no mercado editorial de língua portuguesa, conhecido pelo seu importante papel nas circulações transnacionais.

Sousa Pinto fundou três editoras: Livros de Portugal, em 1941, a Edições Dois Mundos, em 1942, no Rio de Janeiro, e a Livros do Brasil, em 1944, em Lisboa ${ }^{14}$. O

\footnotetext{
${ }^{12}$ Para mais informações, ver: FERREIRA, 2013.

${ }^{13}$ Como salienta Carlos Mendes de Sousa, tal entusiasmo só se repete nos anos sessenta. Os romances, entretanto, publicados pela autora não foram completamente ignorados nem extremamente elogiados pela crítica literária no Brasil (SOUSA, 2000). Sobre a recepção dos primeiros romances de Lispector no Brasil, ver páginas 57-106.

${ }^{14}$ As editoras Livros de Portugal e Edições Dois Mundos foram fruto do trabalho de uma empresa formada pelo jovem Sousa Pinto e dois editores portugueses experientes, proprietários de editoras em Lisboa e Porto: Pedro Ferreira de Andrade e Américo Fraga Lamares. Mais tarde, a "Livros do Brasil" foi fundada por Sousa Pinto e o seu irmão, Joaquim de Sousa Pinto. O diálogo entre estas editoras é visível pela existência de elementos gráficos comuns nas obras publicadas, na tipografia, estilo, cores e disposição dos livros. Ver: MEDEIROS, 2018, p. 212-232.
} 
contato entre a autora brasileira e o editor fez-se através de Thiers Martins Moreira (19041970). Entre 1960 e 1962, Moreira foi professor visitante na Universidade de Lisboa e ocupou a cátedra de Estudos Brasileiros, o que lhe permitiu participar na publicação de Lispector em Portugal, e zelar para que seu texto preservasse a língua portuguesa na sua variante brasileira, sem qualquer alteração por parte da editora (LISPECTOR, 2002, loc. 26623$)^{15}$.

Nessa altura, Lispector já tinha publicado quatro romances e três livros de contos, mas a editora Livros do Brasil escolheu "Perto do Coração Selvagem" (1943), o primeiro romance de Lispector. Este seria aquele mais frequentemente republicado em Portugal. Vale à pena notar que a publicação foi proibida de circular no Brasil na altura, como é afirmado na capa do livro.

Como parte da estratégia promocional, a Livros do Brasil publicou uma entrevista exclusiva com a autora em seu Boletim Bibliográfico, bem como um ensaio sobre o livro (GONÇALVES, 2018, p. 78; 82). No mesmo ano, o crítico português Taborda de Vasconcelos publicou igualmente uma crítica no jornal Comércio do Porto ${ }^{16}$.

A edição de Sousa Pinto não incluía um prefácio ou um posfácio, mas uma simples contracapa em que se lia:

Editando o romance "Perto do Coração Selvagem", Livros do Brasil tem a honra de apresentar em Portugal Clarice Lispector, um dos nomes mais prestigiosos da ficção brasileira contemporânea. A par de uma penetrante capacidade de análise psicológica, possui esta ilustre escritora o domínio perfeito da linguagem, que, modelada pela técnica de Joyce e Virginia Woolf, adquire na sua obra uma força e uma originalidade expressivas verdadeiramente excepcionais (LISPECTOR, 1961, contracapa).

\footnotetext{
15 A exigência da Lispector não é anódina, dado que em 1955 a escritora brasileira Rachel de Queiroz queixou-se publicamente na revista mais popular do Brasil, "O Cruzeiro", sobre seu editor português, que era, nada mais nada menos, que Sousa Pinto. Ele tinha exigido como condição de publicação que os livros da autora fossem "traduzidos" para o português de Portugal. Indicando que esta língua era "um patrimônio tanto quanto nosso quanto seu", Queiroz rejeitou a proposta da editora. Ver: QUEIROZ, 1955, p. 114.

${ }^{16}$ Documento Livros do Brasil: correspondência de 18 de dezembro de 1961, 1fl. (CL/cp071). Arquivos da Fundação Casa de Rui Barbosa, Rio de Janeiro.
} 
Imagem 1: Capa da primeira edição de livro de Clarice Lispector por editora portuguesa. 1961

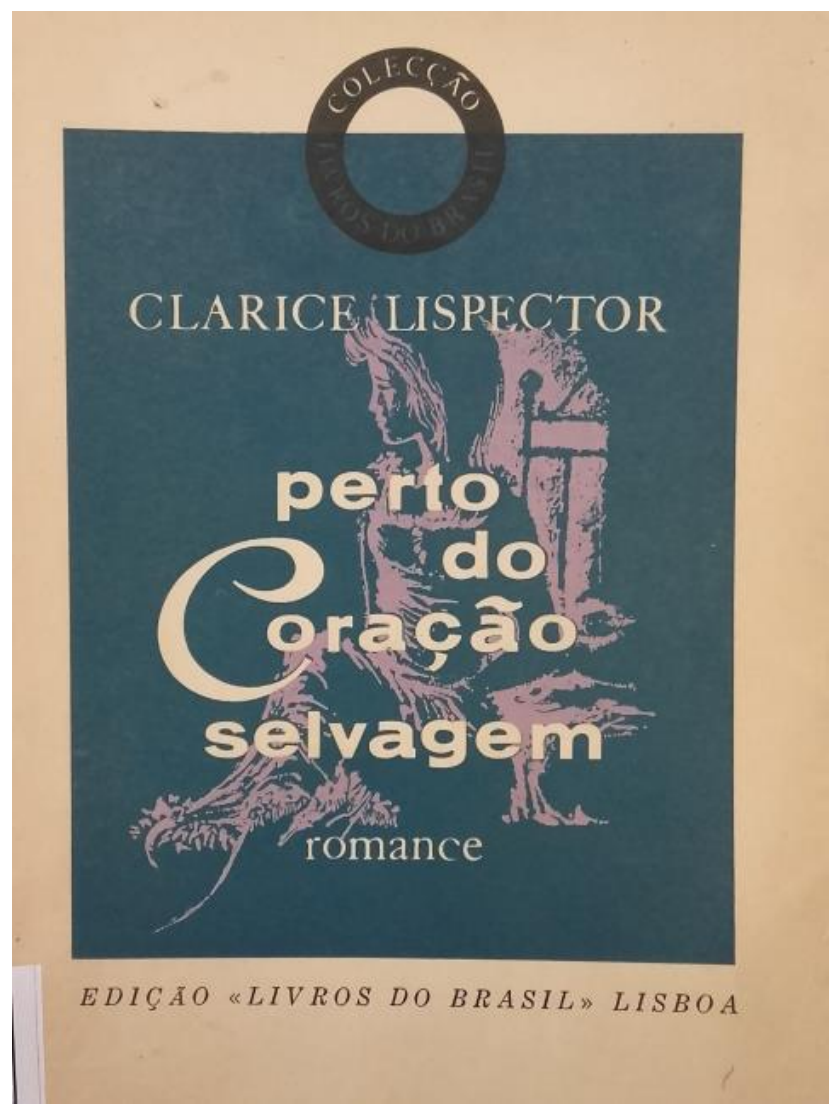

Fonte: Lispector, Clarice. Perto do coração Selvagens. Lisboa: Livros do Brasil, 1961. Biblioteca Nacional de Portugal (foto da autora)

Os anos 60 marcam uma virada na trajetória literária de Clarice Lispector. Segundo Benedito Nunes, a recepção da sua obra no Brasil pode ser dividida em duas fases: a primeira, entre 1943 e 1959, caracterizou-se por uma circulação restrita à crítica literária e a alguns escritores. A segunda fase começou com a publicação da coleção de contos "Laços de família", em 1960, seguida da colaboração com o "Jornal do Brasil" a partir de 1967, o que atraiu a atenção do público acadêmico e dos leitores do jornal (NUNES, 1982, p. 13) ${ }^{17}$.

Em 1961, em Portugal, apenas três autoras já tinham sido publicadas por Antônio Sousa Pinto na "Livros do Brasil": Clarice Lispector, Lygia Fagundes Telles e Carolina Nabuco. Das quarenta e sete obras publicadas desde 1944 pela editora, dezesseis foram

${ }^{17}$ É importante mencionar que o número de estudantes no Brasil aumentou de 44.100 em 1950 para um milhão em 1975, em um período que coincide com o boom de Clarice Lispector no mundo acadêmico. Ver HALLEWELL, 1985, p. 576. 
de Érico Veríssimo, duas de Jorge Amado, dez de José Lins do Rêgo e cinco de Gilberto Freyre $^{18}$. Quatro autores então identificados com o movimento regionalista brasileiro.

Depois desta primeira publicação, porém, só vinte e sete anos depois é que a Círculo de Leitores, editora fundada em 1970, e uma das mais respeitadas editoras portuguesas, voltou a publicar Clarice Lispector em Portugal ${ }^{19}$. Próxima de círculos universitários, Círculo de Leitores pertencia à empresa alemã Bertelsmann, o maior grupo editorial da Europa na época.

No Portugal salazarista, no qual um quarto da população era ainda analfabeta ${ }^{20}$, a Círculo de Leitores apresentava um ambicioso projeto de educação literária popular, publicando clássicos da literatura portuguesa e mundial. A editora funcionou como clube do livro e publicou uma revista promocional para assinantes. Na Espanha, em Portugal e no Brasil, as empresas Bertelsmann também investiram na venda à domicílio. No final da década de 1970, tinham cerca de 360.000 assinantes em Portugal e mais de 500.000 no Brasil (HALLEWELL, 1985, p. 573).

Em 1988, Clarice Lispector não foi publicada como autora brasileira, mas sim como uma autora com um estilo único e particular. A interpretação feminista da sua obra, especialmente elaborada na França, não aparece nos paratextos desta segunda edição. Pelo contrário, o livro reforça a imagem de uma escritora lusófona cuja obra tem um alcance universal. "Perto do coração selvagem" é então apresentado por Eduardo do Prado Coelho (1944-2007), crítico literário e representante da "nova crítica" em Portugal, professor na Universidade Nova de Lisboa. O livro, publicado primeiramente pela Livros do Brasil e, em seguida, pela Círculo de Leitores, contribuiu, assim, para a divulgação da obra de Clarice Lispector em Portugal, embora em círculos ainda restritos.

Levanta-se a questão de saber se a obra da autora também haveria circulado em Portugal através de edições brasileiras até 1990. Laurence Hallewell mostra, no entanto, que a exportação de livros brasileiros para Portugal nunca excedeu o valor das

\footnotetext{
${ }^{18}$ Ver a segunda capa de LISPECTOR, 1961.

${ }^{19}$ A minha hipótese para explicar a ausência de novas edições da Lispector em Portugal após 1961 é uma certa dificuldade encontrada pelos brasilianistas em Portugal nos anos 60 e 70 para promover o seu campo de estudo no contexto acadêmico salazarista. Um novo sopro de vida foi possível quando Eduardo Prado Coelho entrou na universidade portuguesa após a Revolução dos Cravos, pois foi ele quem parece ter relançado a difusão da literatura brasileira junto do público português e escreveu a introdução à segunda edição do "Perto do Coração Selvagem", em 1988.

20 Base de Dados Portugal Contemporâneo [online]. Disponível em: https://www.pordata.pt/Portugal/Taxa+de+analfabetismo+segundo+os+Censos+total+e+por+sexo-2517. Acesso em: 10 abr.2019..
} 
importações $^{21}$. Por conseguinte, é difícil afirmar que as edições brasileiras de Clarice Lispector tenham circulado em Portugal, nessa altura, fora dos poucos círculos intelectuais interessados no Brasil que transportavam por conta própria seus exemplares. $\mathrm{O}$ acesso à obra de Lispector parece estar restrito a um público leitor muito diminuto, como foi também o caso durante muito tempo no Brasil:

Situemos melhor o público de Clarice Lispector [no Brasil]. Em meio à hegemonia artística de tendências literárias com ênfase no social, o leitor de nossa escritora é o mesmo que consome, na década de 60, literatura de vanguarda. Ele é atraído pela problematização radical da linguagem e pela tematização de motivos existenciais que pautavam o trabalho artístico de Clarice Lispector. Logo, nas condições do círculo comunicativo brasileiro, o leitor é também de nível universitário (ABDALA JÚNIOR \& CAMPEDELLI, 1996, p. 197).

Um novo impulso se fez sentir logo no início do século XXI, iniciando uma terceira fase destas circulações, dada a crescente popularidade da autora brasileira em Portugal. Este novo momento é caracterizado pelo projeto editorial da Relógio d'Água, casa editorial portuguesa fundada em 1983. A compra dos direitos das obras da autora por esta empresa coincidiu com a promoção da sua obra no Brasil pelas Edições Rocco.

A Relógio d'Água é hoje uma das mais importantes editoras em Portugal, apesar da sua modesta dimensão. Tem uma equipe de cerca de dez funcionários, comandada por Francisco Vale. A empresa tem um catálogo de mais de 1.300 obras, desde poesia a prosa de ficção, traduzidas ou originais em português, em vários gêneros, tais como teatro, artes, comunicação, literatura infantil, humanidades, filosofia, música, arquitetura ou cinema. Inclui autores brasileiros como Carlos Drummond de Andrade, Manuel Bandeira e Cecília Meireles, no campo da poesia, e Clarice Lispector em prosa. A Relógio d'Água também trabalha em parceria com outras editoras, tais como Assírio \& Alvim e Cotovia ${ }^{22}$, especialmente na publicação de livros destinados ao público universitário e de livros de bolso $^{23}$. É no quadro de tal parceria que a edição de "Laços de Família" pela Cotovia,

\footnotetext{
21 Os números da importação-exportação mais ou menos equilibram-se a partir dos anos 70 . Ver: HALLEWELL, 1985, p. 296-297.

${ }^{22}$ Sobre a estrutura e a missão da "Relógio d'Água", ver: RODRIGUES, 2013 e VALE, 2009.

${ }^{23}$ É importante notar que em Portugal e no Brasil, os livros de bolso não têm a mesma importância no mercado editorial que noutros países, tais como a França. Os mercados lusófonos apresentam uma grande variedade na produção de livros (tamanho, tipografia, capa, cores, visuais, qualidade do papel, etc.).
} 
com posfácio do professor da Universidade do Minho, Carlos Mendes de Sousa, é publicada em 2006, 2008 e $2013^{24}$.

Imagem 2: Edição de livro de Clarice Lispector para fins educacionais

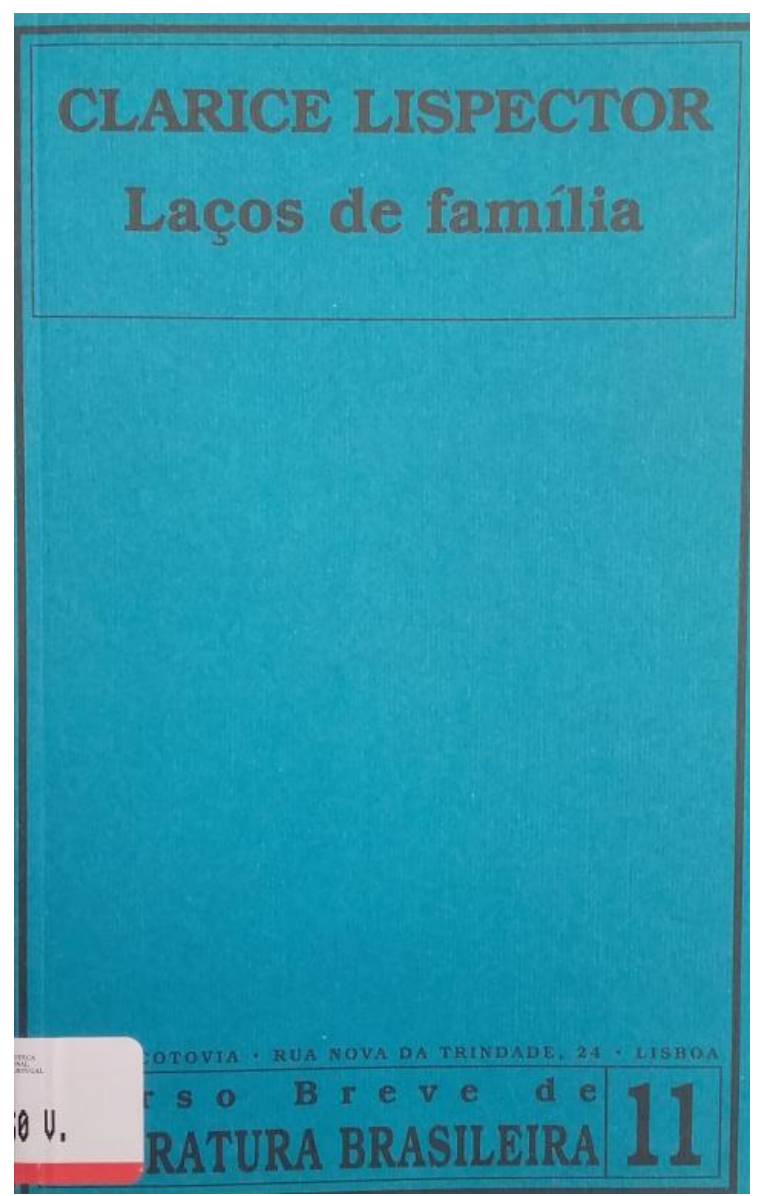

Fonte: Lispector, Clarice. Laços de Família. Lisboa: Cotovia, 2006. Biblioteca Nacional de Portugal. (foto da autora)

As tentativas de encontrar os editores da Rocco e da Relógio d'Água têm sido infrutíferas até agora, e continuo à espera de alguns elementos que possam ajudar a elucidar as ligações óbvias entre os projetos editoriais destas duas editoras em torno da obra de Clarice Lispector. Meu argumento aqui, no entanto, baseia-se em três pistas convincentes: ambas as editoras utilizam ilustrações da artista brasileira Flor Opázio para as capas de alguns dos livros de Clarice Lispector. Além disso, as duas mais recentes

\footnotetext{
${ }^{24}$ Relógio d'Água, em vez de favorecer lançamentos de livros, conferências ou apresentações para otimizar as suas vendas, prefere operar através de uma rede e enviar primeiro os seus lançamentos para os meios de comunicação. Em Portugal, a publicação dos livros da Lispector foi acompanhada por comentários críticos da RTP, TSF e dos jornais Público, Expresso, Jornal de Letras, Agenda Cultural de Lisboa etc.
} 
publicações póstumas da escritora, "Todos os contos" e "Todas as crônicas", têm as mesmas capas e trabalho editorial em ambos os países, e o blog da Relógio d'Água reproduz frequentemente anúncios feitos pela Rocco no Brasil.

Contudo, embora a editora portuguesa utilize os desenhos de Flor Opázio nos livros infantis escritos por Lispector, difere da editora brasileira Rocco quando se trata da publicação dos romances e contos. A escolha do rosto de Lispector na capa é o fio condutor destas publicações portuguesas: uma dúzia de livros são acompanhados por diferentes fotografias da autora, realçando a sua juventude, sensualidade e beleza.

Imagem 3: Capas de livros de Clarice Lispector publicados pela editora Relógio

$$
\text { D’Água }
$$
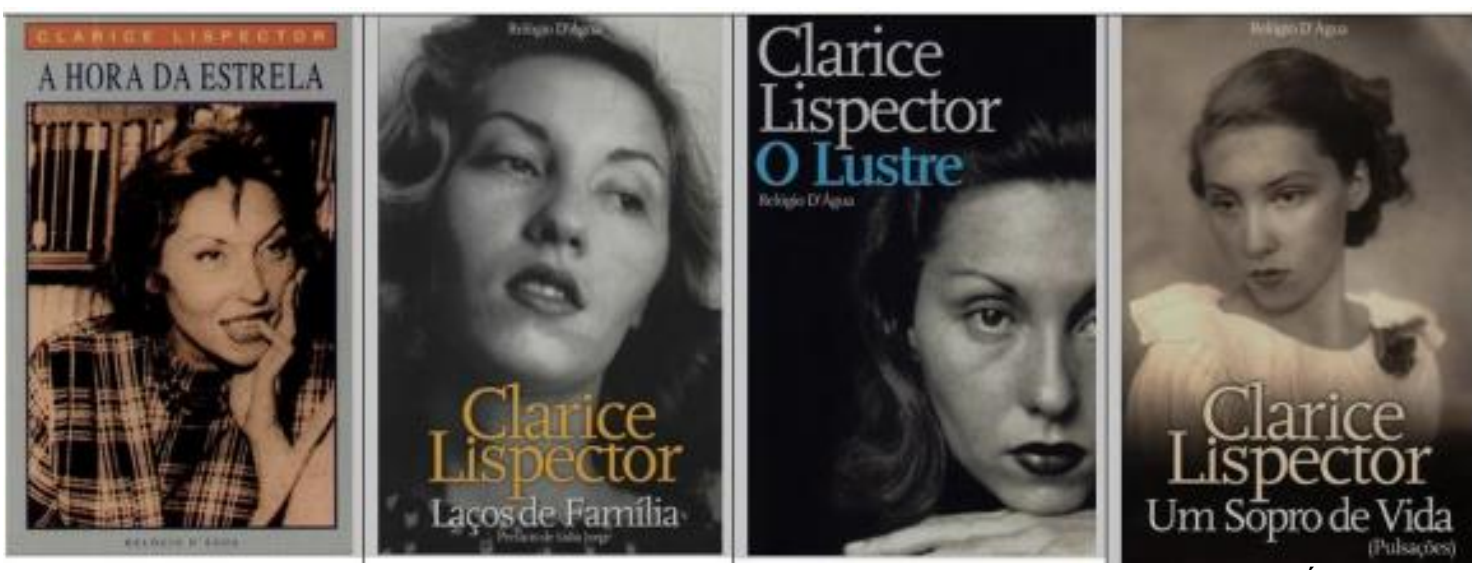

Fonte: Capas dos livros de Clarice Lispector (“A hora da estrela”. Lisboa: Relógio d'Água, 2002 ; "Laços de Família”. Lisboa: Relógio d'Água 2012 ; "O Lustre”. Lisboa: Relógio d’Água, 2012 ; “Um sopro de vida”. Lisboa: Relógio d’Água, 2013).

A editora portuguesa foi também selecionada em 2011 pelo governo brasileiro para beneficiar de um edital para a promoção de autores brasileiros nos países da Comunidade dos Países de Língua Portuguesa $\left(\mathrm{CPLP}^{25}\right)$ : este consistiu no financiamento de certas publicações. Além disso, a Relógio d'Água aparece nas listas do Plano Nacional de Leitura (PNL), elaboradas pelo governo português para orientar professores nas escolas. Estão incluídos aí vários títulos de Clarice Lispector, incluindo livros, contos e romances infantis:

\footnotetext{
25 "Relógio D'Água, Cotovia e Ecopy com bolsa para publicar autores brasileiros", Público [online]. Disponível em: https://www.publico.pt/2012/10/30/culturaipsilon/noticia/relogio-dagua-cotovia-e-ecopycom-bolsa-para-publicar-autores-brasileiros-1569420. Acesso em: 30 mai. 2018.
} 
Quadro 1: Lista de livros de/sobre a Clarice Lispector recomendados pelo PNL2027 para os anos 2017 e 2018 em Portugal

\begin{tabular}{|c|c|c|c|}
\hline Titre & Auteur & Maison d'édition & Année \\
\hline A vida íntima de Laura & Clarice Lispector & Relógio d'Água & 2017 \\
\hline O mistério do coelho pensante & Clarice Lispector & Relógio d'Água & 2017 \\
\hline Quase de verdade & Clarice Lispector & Relógio d'Água & 2017 \\
\hline A mulher que matou os peixes & Clarice Lispector & Relógio d'Água & 2017 \\
\hline $\begin{array}{c}\text { Clarice Lispector para meninas } \\
\text { e meninos }\end{array}$ & Nádia Fink & Tinta-da-China & 2018 \\
\hline A hora da estrela & Clarice Lispector & Relógio d'Água & 2018 \\
\hline A paixão segundo GH & Clarice Lispector & Relógio d'Água & 2018 \\
\hline Laços de Família & Clarice Lispector & Relógio d'Água & 2018 \\
\hline Perto do coração selvagem & Clarice Lispector & Relógio d'Água & 2018 \\
\hline
\end{tabular}

Fonte: Plano Nacional de Leitura PNL 2017. Disponível em:

http://www.planonacionaldeleitura.gov.pt/data/listas/58_Todas\%20as\%20listas_2017.pdf e http://www.pnl2027.gov.pt/np4/\%7B \$clientServletPath\%7D/?newsId=230\&fileName=Livros_recomend ados_PNL_1_semestre_2018.pdf. Acesso em: 30 de nov. $2019^{26}$.

É, então, de se notar que a Relógio d'Água desempenha agora um papel fundamental na divulgação da obra de Clarice Lispector em Portugal.

\section{Leituras de Clarice Lispector em Portugal}

Existem em 2020 trinta e duas entradas para "Clarice Lispector-autor" na Base

Nacional de Dados Bibliográficos em Portugal. Este é um número menor do que na Espanha, em que aparecem quarenta e uma, ou na França, em que existem quarenta e duas:

Quadro 2: Registo das obras de Clarice Lispector na Base de Dados Bibliográficos Nacional Portuguesa

\begin{tabular}{|c|c|c|c|}
\hline $\begin{array}{c}\text { Année de } \\
\text { Publication }\end{array}$ & Titre & $\begin{array}{c}\text { Maison } \\
\text { d'Édition }\end{array}$ & Préface/postface \\
\hline 1961 & $\begin{array}{c}\text { Perto do Coração } \\
\text { Selvagem }\end{array}$ & Livros do Brasil & - \\
\hline 1988 & $\begin{array}{c}\text { Perto do Coração } \\
\text { Selvagem }\end{array}$ & $\begin{array}{c}\text { Círculo de } \\
\text { Leitores }\end{array}$ & Eduardo Prado Coelho \\
\hline 1990 & Laços de Família & Relógio d'Água & Lídia Jorge \\
\hline 1990 & Onde estivestes de noite & Relógio d'Água & - \\
\hline 1999 & $\begin{array}{c}\text { Uma aprendizagem ou o } \\
\text { Livro dos Prazeres }\end{array}$ & Relógio d'Água & - \\
\hline
\end{tabular}

${ }^{26}$ Ver igualmente FACINA, 2018.

Revista Escritas do Tempo - v. 3, n. 8, mai-ago/2021 - p. 99-121 
DOI: 10.47694/issn.2674-7758.v3.i8.2021.99121

\begin{tabular}{|c|c|c|c|}
\hline 2000 & $\begin{array}{c}\text { Perto do coração } \\
\text { selvagem }\end{array}$ & Relógio d'Água & - \\
\hline 2000 & A paixão segundo $G H$ & Relógio d'Água & - \\
\hline 2000 & A maçã no escuro & Relógio d'Água & - \\
\hline 2002 & A hora da estrela & Relógio d'Água & - \\
\hline 2004 & A Descoberta do mundo & Indícios de Oiro & $\begin{array}{l}\text { Carlos Mendes de } \\
\text { Sousa }\end{array}$ \\
\hline 2006 & Laços de Família & Cotovia & $\begin{array}{c}\text { Carlos Mendes de } \\
\text { Sousa }\end{array}$ \\
\hline 2006 & Contos & Relógio d'Água & - \\
\hline 2008 & Laços de família & Cotovia & $\begin{array}{c}\text { Carlos Mendes de } \\
\text { Sousa }\end{array}$ \\
\hline 2009 & A cidade sitiada & Relógio d'Água & - \\
\hline 2011 & $\begin{array}{l}\text { Perto do coração } \\
\text { selvagem }\end{array}$ & Relógio d'Água & - \\
\hline 2011 & $\begin{array}{l}\text { Perto do coração } \\
\text { selvagem }\end{array}$ & Relógio d'Água & - \\
\hline 2012 & Água viva & Relógio d'Água & - \\
\hline 2012 & O lustre & Relógio d'Água & - \\
\hline 2012 & Um sopro de vida & Relógio d'Água & - \\
\hline 2012 & A vida intima de Laura & Relógio d'Água & - \\
\hline 2012 & $\begin{array}{l}\text { A mulher que matou os } \\
\text { peixes }\end{array}$ & Relógio d'Água & - \\
\hline 2013 & Quase de verdade & Relógio d'Água & - \\
\hline 2013 & $\begin{array}{c}\text { O mistério do coelho } \\
\text { pensante }\end{array}$ & Relógio d'Água & - \\
\hline 2013 & A paixão segundo $G H$ & Relógio d'Água & - \\
\hline 2013 & A maçã no escuro & Relógio d'Água & - \\
\hline 2013 & A descoberta do mundo & Relógio d'Água & - \\
\hline 2013 & $\begin{array}{c}\text { Uma aprendizagem ou o } \\
\text { livro dos prazeres }\end{array}$ & Relógio d'Água & - \\
\hline 2013 & Laços de Família & Cotovia & $\begin{array}{c}\text { Carlos Mendes de } \\
\text { Sousa }\end{array}$ \\
\hline 2014 & A paixão segundo $G H$ & $\begin{array}{l}\text { Vista Alegre } \\
\text { Atlantis }\end{array}$ & - \\
\hline 2016 & Todos os contos & Relógio d'Água & Benjamin Moser \\
\hline 2018 & Correio para mulheres & Relógio d'Água & - \\
\hline 2018 & Todas as crônicas & Relógio d'Água & $\begin{array}{l}\text { Marina Colasanti et } \\
\text { Pedro Karp Vasquez }\end{array}$ \\
\hline
\end{tabular}

Fonte: Biblioteca Nacional de Portugal

A fim de melhor historicizar a recepção de Clarice Lispector em Portugal, destaco três momentos, cada um dos quais correspondendo ao papel-chave desempenhado por três mediadores. O primeiro período é caracterizado pela publicação de alguns textos de João Gaspar Simões, crítico literário e intelectual prolífico, que publicou em ambos os 
lados do Atlântico. Especialista em literatura brasileira contemporânea, foi um dos intelectuais portugueses que celebrou a transição no Brasil de uma literatura regionalista a uma literatura brasileira mais "universal", preocupada antes de mais nada com "o ser humano" em suas subjetividades (SIMÕES, 1950b, p. 2).

João Gaspar Simões publicou o primeiro artigo sobre "Perto do Coração Selvagem" em Portugal em 1945, no qual afirmou que o livro introduziu o "monólogo interior sistemático na história do romance brasileiro"27. Em 1950, Simões publicou uma análise de "A Cidade Sitiada", livro publicado por Lispector em 1948, no "Jornal no Brasil”, no qual desqualificou sua anterior definição de monólogo interior em Clarice Lispector, preferindo a definição de uma escrita que parte do centro (do sujeito) para a periferia (o exterior), refletindo uma "consciência conceitual do mundo" (SIMÕES, 1950a, p. 1).

O mesmo artigo foi retomado em 1964 por Simões em um livro em que a obra de Lispector é lida através do prisma do existencialismo francês. O autor afirma que "Com Clarice Lispector principiava a era do cosmopolitismo numa literatura em que dominara até então o regionalismo nordestino" (SIMÕES, 1964, p. 313). O crítico literário também questiona o interesse que a obra de Lispector poderia suscitar aos olhos de um leitor português à época: “Como reagirão os leitores portugueses a este romance, tão estranho à sua mentalidade? Clarice merece ser lida"28 (SIMÕES, 1964, p. 316).

Estes primeiros textos de Simões foram seguidos por análises mais sistemáticas que surgiram durante os anos 70, em uma segunda fase da recepção da obra de Clarice Lispector em Portugal, que se caracteriza pelo papel desempenhado pela universidade. Manifesta-se principalmente nas páginas de revistas especializadas em literatura como “Colóquio Letras”, periódico publicado pela Fundação Calouste Gulbenkian.

João Marques Lopes destaca o papel importante desempenhado pela revista na constituição do campo dos estudos literários brasileiros entre 1971 e 1996 em Portugal. Clarice Lispector e João Guimarães Rosa foram os dois escritores brasileiros aí mais frequentemente mencionados (LOPES, 2012). De fato, enumeramos seis artigos publicados nesta revista por autores brasileiros e portugueses, que tratam da obra de

\footnotetext{
${ }^{27}$ O texto original publicado por João Gaspar Simões na imprensa portuguesa em 1945 não foi encontrado, mas Ribeiro Couto refere-se a ele. Ver: Arquivos da Fundação Casa de Rui Barbosa. Fundo Clarice Lispector. Correspondência de Ribeiro Couto para Clarice Lispector, Lisboa, 29/07/1955, 2fl. (CL/cp 030). ${ }^{28}$ Joana Matos Frias discorda desta afirmação, argumentando que o público português já tinha experiência prévia com este tipo de gênero. Ver FRIAS, 2004, p. 45)
} 
Lispector. Entre os brasileiros, notamos a presença do filósofo e professor Benedito Nunes, que se estabeleceu como especialista da obra da autora, a partir da publicação em 1966 de "O mundo de Clarice Lispector", e em 1973 de "Leitura de Clarice Lispector" (MOSER, 2009, p. 616-617).

Para além dos brasileiros, Eduardo Prado Coelho desempenhou um papel na divulgação da autora em Portugal através da publicação de artigos, capítulos de livro e a introdução a "Perto do coração selvagem", na publicação de 1988:

São diversos os caminhos para chegar a "Perto do Coração Selvagem". Mas só encontraremos acolhimento nas páginas deste livro se o soubermos ler a partir de Bach, Deus, ou da natureza abstrata das palavras. Mesmo que uma tal experiência se revele inesperada e definitivamente sísmica (COELHO, 1988, p. VIII).

Prado Coelho propõe, assim, uma visão menos tradicional, mais subjetiva e que enfatiza a experiência da leitura:

Existe uma [autora] a que me sinto ligado por qualquer coisa que excede não apenas o Brasil, mas a literatura: falo de Clarice Lispector. Porque, quando se lê Clarice, entra-se numa experiência sem regresso (...). Tenho diante de Clarice o que me basta de não entender (COELHO, 1984, p. 42).

Em 1982, Prado Coelho dirigiu um número do "Jornal Expresso" dedicado ao Brasil. Em artigo presente neste número, Arnaldo Saraiva volta-se à gênese dos estudos brasileiros em Portugal, em 1916, e acusa as reformas educacionais de serem responsáveis pela falta de interesse do sistema universitário português pelo tema, uma vez que as disciplinas relacionadas com o Brasil (história e literatura) se tornaram facultativas na maioria dos cursos universitários desde então e até os anos 1980 (SARAIVA, 1984, p. 42B).

Acredito que a terceira fase da recepção de Lispector em Portugal corresponde justamente à superação do círculo acadêmico. Baseio-me aqui em uma análise da imprensa contemporânea portuguesa, em particular dos jornais "Público", "Expresso" e "Jornal de Letras", em que o nome da autora aparece frequentemente.

Esta fase coincide com o boom de Clarice Lispector em Portugal, que se compreende pela política editorial da Relógio d'Água, paralela à da editora Rocco no Brasil, pela promoção que faz o governo brasileiro de Clarice Lispector em Portugal e por dois grandes eventos: a realização em 2009 de um simpósio dedicado à obra da escritora na Casa Fernando Pessoa, em Lisboa, com a presença de especialistas 
portugueses e brasileiros ${ }^{29}$, e as celebrações em 2013 como parte do "Ano do Brasil em Portugal", marcado pela exposição "Clarice Lispector: a hora da estrela" na Fundação Calouste Gulbenkian, também em Lisboa.

Este terceiro momento é igualmente marcado pelo papel de Carlos Mendes de Sousa, professor da Universidade do Minho. Este é hoje reconhecido, em Portugal e no Brasil, como um dos mais eminentes especialistas da obra de Clarice Lispector, desde a publicação de sua tese de doutoramento em 2000 em Portugal e depois no Brasil, pelo Instituto Moreira Salles.

Neste livro, Mendes de Sousa apresenta de uma forma interessante a questão da importância da língua portuguesa em Clarice Lispector, muito baseado na teoria deleuziana: "o território da literatura passará a ser para Clarice um horizonte de busca nascido da tensão entre o efeito desterritorializador e a instauração de um espaço nos próprios limites da língua a que deseja, de fato, pertencer” (SOUSA, 2000, p. 32).

Efetivamente, tal definição ilustra o trabalho de Lispector com sua matéria-prima, que é a língua portuguesa:

O que eu recebi de herança não me chega. Se eu fosse muda, e também não pudesse escrever, e me perguntassem a que língua eu queria pertencer, eu diria: inglês, que é preciso e belo. Mas como não nasci muda e pude escrever, tornouse absolutamente claro para mim que eu queria escrever em português. Eu até queria não ter aprendido outras línguas: só para que minha abordagem do português fosse virgem e límpida (LISPECTOR, 1968, p. 2)

Gostaria de encerrar este trabalho com uma última questão, a da intertextualidade. Consultando os catálogos de teses de doutorado e dissertações de mestrado defendidas desde 2000 nos diferentes cursos de formação em estudos brasileiros em Portugal, encontrei dezessete referências à obra de Clarice Lispector. A questão da autoria feminina está adquirindo agora um lugar significativo ${ }^{30}$ e é tema frequentemente abordado no interior dos estudos de literatura comparada, na análise da obra de Lispector junto à de outras escritoras como Katherine Mansfield, Virginia Woolf, Marguerite Duras, Inês Pedrosa, Adília Lopes ou Maria Teresa Horta.

29 Ver: Obra de Clarice Lispector em debate na Casa Fernando Pessoa. Disponível em: https://www.rtp.pt/noticias/cultura/obra-de-clarice-lispector-em-debate-na-casa-fernandopessoa_n211451. Acesso em: 20 abr. 2019.

30 É preciso, no entanto, mencionar aqui uma iniciativa mais antiga, a única anterior aos anos 2000 encontrada por esta pesquisa: CRISTOVÃO, 1980. 
Maria Teresa Horta (1937), tornou-se um ícone em Portugal em 1972, quando sofreu a prática da censura salazarista juntamente com Maria Isabel Barreno e Maria Velho da Costa por conta da publicação do livro "Novas Cartas Portuguesas" "31. As três escritoras deste livro, então considerado como provocador, foram a julgamento. Este foi interrompido e anulado por conta do advento da Revolução dos Cravos em 25 de Abril de 1974. O livro tornou-se um símbolo em Portugal e foi associado ao movimento de libertação das mulheres, embora as autoras não se identificassem necessariamente com o feminismo.

Maria Teresa Horta inspirou-se em Clarice Lispector para criar duas ficções contemporâneas. O conto "Sem culpa”, publicado em 2012, aparece em diálogo com o conto "Cem anos de perdão", publicado por Clarice Lispector em 1971. Mas a intertextualidade é ainda mais evidente em "A paixão segundo Constança H”, livro publicado por Maria Teresa Horta em 1994, cujo título se refere explicitamente ao romance de Lispector “A paixão segundo GH” (1964). Horta inicia o livro com uma citação de Lispector: "Estou procurando, estou procurando. Estou tentando entender. Aconteceu-me alguma coisa que eu, pelo fato de não a saber como viver, vivi uma outra?" (LISPECTOR, 1998, p. 11). A referência pode servir para ilustrar os temas da alucinação e da suposta loucura, presentes na narrativa da personagem Constança:

Parece-nos, portanto, que ambas as romancistas, ao levar ao limite a indagação sobre as possibilidades ontológicas da linguagem, acabam por revelar um preceito socrático: "a tomada de consciência de si através da consciência da significação das palavras" ajuda os sujeitos a descobrir a "verdade de si mesmos", necessária ao seu crescimento. Em ambas as romancistas, a questão da linguagem entrelaça-se com as duas formas de desejo, na ótica platônica: o "desejoaspiração" e o "desejo-apetite" (FARIA, 2015, online).

O trabalho com a linguagem, nas fronteiras da loucura e do misticismo, em uma busca de verdades (Horta) ou do "neutro" (Lispector), caracterizaria, assim, as duas autoras, dois ícones literários femininos nos seus respectivos países.

Clarice Lispector faleceu em 9 de dezembro de 1977, sem ter tido tempo de acompanhar pessoalmente a circulação internacional da sua obra. Em Portugal, ela começou a circular entre pequenos grupos intelectuais e acadêmicos interessados pelo

\footnotetext{
${ }^{31}$ A professora Ana Luísa Amaral (Universidade de Porto) coordena o projeto "Novas Cartas Portuguesas, 40 Anos Depois », no qual documentos relativos à polêmica em torno do livro são acessíveis online: http://www.novascartasnovas.com. Acesso em: 10 nov. 2019.
} 
Brasil. No entanto, a partir dos anos 2000, tem estado disponível em todas as livrarias do país, graças ao esforço conjunto de vários atores importantes: os governos brasileiro e português, a editora responsável pela sua obra, a imprensa e o mundo acadêmico. A autora brasileira que levou ao limite a busca das fronteiras da linguagem tornou-se uma escritora cujo nome é agora familiar aos leitores em Portugal.

\section{Conclusão}

Depois de ter traçado rapidamente, neste artigo, os caminhos da internacionalização da obra de Clarice Lispector, interessei-me pelo estudo de sua circulação em Portugal. A publicação dos livros da autora no país foi tardia em relação à França, e só muito recentemente é que foi sistematizada e popularizada. Em Portugal, com exceção de "Perto do Coração Selvagem", sua obra só começou a ser publicada sistematicamente nos anos 90, enquanto à mesma época na França já havia mais de dez títulos publicados (PEREIRA, 1995, p. 109-125), sete na Alemanha (CASTRO, 2016, p. 40-41), seis na Espanha (ARF, 2015, 17-29) e nove em língua inglesa (BARBOSA, 1994, p. 15-18).

A leitura dos artigos científicos publicados sobre a autora antes dos anos $2000 \mathrm{em}$ Portugal não revela uma grande influência da leitura feminista promovida por Hélène Cixous na França, tão importante, no entanto, para compreender a divulgação de Lispector na Alemanha, nos Estados Unidos ou na Inglaterra.

Parece-me, neste sentido, que o intercâmbio científico aconteceu entre países de língua portuguesa até 1990, em vez da importação de leituras de outros sistemas linguísticos ou de outras redes acadêmicas. Mais recentemente, no entanto, a importância das teorias feministas e de gênero produzidas nos Estados Unidos e na França nos estudos literários sobre Lispector pode ser encontrada em Portugal.

A circulação da obra da Lispector em Portugal é sobretudo um reflexo deste diálogo regular entre os campos literários brasileiro e português, as políticas econômicas que afetaram o mercado do livro em língua portuguesa, além das estratégias de divulgação das editoras atualmente detentoras dos direitos da obra de Lispector, e das políticas culturais existentes em ambos os países. Como resultado das iniciativas tomadas pela Relógio d'Água e pelo governo brasileiro nos anos 2000, o interesse por Clarice Lispector, 
anteriormente restrito aos círculos acadêmicos brasilianistas em Portugal, torna-se amplo e a sua obra mais acessível.

Já a recepção de Lispector em Portugal é marcada por fases que refletem a leitura e a influência predominante de três intelectuais portugueses: João Gaspar Simões, Eduardo do Prado Coelho e Carlos Mendes de Sousa. O fio condutor destas três interpretações é a implementação de uma hermenêutica da obra de Lispector que se liberta do quadro nacional brasileiro, justificando assim a sua promoção em um campo intelectual e acadêmico em geral pouco interessado pela literatura brasileira até os anos 2000. Neste sentido, os três intelectuais portugueses atuam como mediadores culturais. Ainda hoje, os estudos brasileiros em Portugal permanecem vivos graças ao trabalho de professores e professoras de cinco grandes universidades em Lisboa, Coimbra, Porto e Braga $^{32}$.

Assim, a obra de Clarice Lispector circula dentro desta complexa teia formada pelas múltiplas ligações entre o campo literário, o mercado do livro, o mundo acadêmico, a mídia e outros mediadores em Portugal; todos os atores que participaram de diversas formas na promoção da dimensão universal da obra desta escritora brasileira de língua portuguesa.

\section{Referências}

\section{Fontes:}

Arquivos da Fundação Casa de Rui Barbosa. Fundo Clarice Lispector. Correspondência de Ribeiro Couto para Clarice Lispector, Lisboa, 29/07/1955, 2fl. (CL/cp 030).

Arquivos da Fundação Casa de Rui Barbosa. Documento Livros do Brasil: correspondência de 18 de dezembro de 1961, 1fl. (CL/cp071).

Biblioteca Nacional de Portugal. Setor de periódicos. SARAIVA, Arnaldo. Literatura Brasileira. In: COELHO, Eduardo Prado (org.), Especial Brasil, Jornal Expresso, 18/02/1984, p. 42B.

Biblioteca Nacional de Portugal. Setor de periódicos. COELHO, Eduardo Prado. Clarice Lispector: o instante em que ela é. In: COELHO, Eduardo Prado (org.), Especial Brasil, Jornal Expresso, 18/02/1984, p. 42.

Fundação Biblioteca Nacional. Hemeroteca digital. LISPECTOR, Clarice. Declaração de amor. Jornal do Brasil, 11/05/1968, p. 02.

Fundação Biblioteca Nacional. Hemeroteca digital. SIMÕES, João Gaspar. Clarice Lispector existencialista ou supra-realista? Letras e Artes: suplemento de A manhã, $\mathrm{n}$. 179, 01/10/1950a, p.1.

\footnotetext{
${ }^{32}$ Ver o site da rede de professores brasilianistas em Portugal: https://ebpor.wordpress.com/a-rede/. Ver igualmente entrevista com o professor Abel Barros Baptista BAPTISTA, 2018, p. 43.
} 
Fundação Biblioteca Nacional. Hemeroteca digital. SIMÕES, João Gaspar. Considerações sobre uma Antologia de Contos de Escritores Novos do Brasil. Letras e Artes: suplemento de A manhã, 16/07/1950b, p. 2.

LISPECTOR, Clarice. A paixão segundo G. H. Rio de Janeiro: Rocco, 1998.

LISPECTOR, Clarice. Correspondências. Rio de Janeiro: Rocco Digital, 2002.

LISPECTOR, Clarice. Laços de Família. Lisboa: Cotovia, 2006.

LISPECTOR, Clarice. Perto do Coração Selvagem. Rio de Janeiro: A Noite Editora, 1943.

\section{Bibliografia}

ABDALA JÚNIOR, Benjamin; CAMPEDELLI, Samira Youssef. Vozes da crítica. In: LISPECTOR, Clarice. A paixão segundo G. H., edição de Benedito Nunes, Madrid: Allca XX, 1996, p.196-206.

ARF, Lucilene Machado Garcia. Clarice Lispector e a difusão da sua literatura na Espanha. Olho d'água, n. 7, p. 17-29. 2015.

Associação Brasileira de Imprensa. QUEIROZ, Rachel de Queiroz. Carta de um editor português. O Cruzeiro, 10/09/1955, p. 114.

BAPTISTA, Abel Barros. Entrevista. Opiniães: Revista dos alunos de literatura brasileira - USP, São Paulo, n. 13, p. 40-46, 2018.

BARBOSA, Heloísa Gonçalves. The virtual image: Brazilian Litterature in English Translation. Tese (Doutorado em Estudos Culturais Comparados), The University of Warwick, 1994.

CARRERA, Elena Carrera. The Reception of Clarice Lispector via Hélène Cixous: reading from the Whale's Belly. Arquivo de publicações. Modern Languages, 1999, p. 85-100.

CHEREM, Lúcia Peixoto. As duas Clarices: entre a Europa e a América. Curitiba: Editora UFPR, 2013.

CIXOUS, Hélène Cixous. Vivre l'orange. Paris : Éditions des femmes, 1979.

COELHO, Eduardo do Prado. Clarice: o mistério explica mais do que a claridade. Prefácio. In: LIPSECTOR, Clarice. Perto do coração selvagem. Lisboa: Círculo de Leitores, 1988, p. VIII-XVI.

CRISTÓVÃO, Fernando. Clarice Lispector ou a estética da inevitável ruptura. Revista Cadernos de Literatura, n. 6, p. 61-72, 1980.

DA SILVA, Ana Amália. A recepção de Clarice Lispector nos periódicos acadêmicos britânicos: 1985-2013. In: XVI CONGRESSO INTERNACIONAL ABRALIC, 2015, Belém, Anais...p. 01-12 (Anais eletrônicos) 
DE CASTRO, Thales Augusto Barreto. Um outro olhar sobre a literatura brasileira: Clarice Lispector em tradução alemã. São Paulo: FFLCH/USP, 2016.

DUMAS, Catherine. A propósito do sujeito feminino em literatura contemporânea: A paixão segundo GH de Clarice Lispector, A paixão segundo Constança H de Maria Teresa Horta, Sob o olhar de Medeia de Fiama Hasse Pais Brandão, Passages de Paris, n. 01, p. 102-115, 2005.

FACINA, Taís. Autores brasileiros em terras portuguesas: relação entre Brasil e Portugal no mercado editorial na atualidade. Dissertação (Mestrado em Edição de Texto), Universidade Nova de Lisboa, Lisboa, 2018.

FARACO, Carlos Alberto. História sociopolítica da língua portuguesa. São Paulo: Parábola Editorial, 2016.

FARIA, Ângela Beatriz de Carvalho. Durar é melhor que arder? - A Via Crucis da paixão em Maria Teresa Horta e em Clarice Lispector. Litcult. Publicado em 2015. Disponível em: http://litcult.net/2015/01/30/durar-e-melhor-que-arder-a-via-crucis-da-paixao-emmaria-teresa-horta-e-em-clarice-lispector-2/. Acesso em: 30 mai. 2017.

FERREIRA, Rony Márcio Cardoso. Traduzir pode correr o risco de não parar nunca: Clarice Lispector tradutora (um arquivo). Belas Infiéis, v. 2, p. 175-204. 2013.

FRIAS, Joana Matos. Les Liaisons Dangereuses: Clarice Lispector e Portugal. Metamorfoses, Lisboa: Editorial Caminho, 2004.

GONÇALVES, Bárbara Ribeiro. Letras brasileiras, papéis portugueses: Publicação e publicidade da literatura do Brasil nas páginas do Boletim Bibliográfico Livros do Brasil Lisboa (LBL). Dissertação (Mestrado em Edição de Texto), Universidade Nova de Lisboa, Lisboa, 2018.

HALLEWELL Laurence. O livro no Brasil. São Paulo: Edusp, 1985.

HANES, Vanessa Lopes Lourenço; GUERINI, Andréia. Clarice Lispector traduzida e tradutora. Revista da Anpoll, n. 41, p. 172-183. 2016.

HELENA, Lucia. Nem musa, nem medusa: itinerários da escrita em Clarice Lispector. Rio de Janeiro: Eduff, 2010.

LOPES, João Marques. O romance brasileiro do século XX no campo das revistas literárias portuguesas: o caso da Colóquio Letras (1971-1996). Tese (Doutorado em Estudos Brasileiros), Universidade de Lisboa, Lisboa, 2012.

MEDEIROS, Nuno. O livro no Portugal Contemporâneo. Lisboa: Outro Modo Cooperativa Cultural, 2018.

MIROIR, Jean-Claude. Clarice Lispector e seus tradutores: da fúria à melodia. O eixo e a roda, v. 25, n. 1, p. 61-85. 2016. 
MOSER, Benjamin. Clarice, uma biografia. São Paulo: Cosac\&Naif, 2009.

NUNES, Benedito. Clarice Lispector ou o naufrágio da introspecção. Colóquio Letras, n. 70, p. 13-22, nov. 1982.

PEREIRA, Maria Marta Laus. Aspectos da recepção de Clarice Lispector na França. Anuário de Literatura. n. 3, p. 109-125, 1995.

RODRIGUES, Mônica Álvares Rodrigues. Relatório de estágio na Relógio d'Água. Mestrado em Edição de Texto, Universidade Nova de Lisboa, Lisboa, 2013.

ROZEAUX, Sébastien Rozeaux. Préhistoire de la lusophonie:les relations culturelles luso-brésiliennes au XIXe siècle. Aix-en-Provence : Le Poisson volant, 2019.

SANCHEZ-ELEZ, Maria Victoria Navas. Análise da relação existente entre Clarice Lispector e algumas escritoras portuguesas. Olho d'agua, v. 7, p. 168-181. 2015.

SIMÕES, João Gaspar. Literatura, literatura, literatura...: de Sá de Miranda ao Concretismo Brasileiro. Lisboa: Portugália Editora, 1964.

SORÁ, Gustavo. Traducir el Brasil: una antropología de la circulación internacional de ideas. Buenos Aires: Libros del Zorzal, 2003.

SOUSA, Carlos Mendes. Clarice Lispector: figuras da escrita. Braga: Universidade do Minho/Centro de Estudos Humanísticos, 2000.

2012.

. Clarice Lispector: figuras da Escrita. Rio de Janeiro: Instituto Moreira Salles,

VALE, Francisco Vale. Autores, editores, leitores. Lisboa: Relógio d'Água, 2009.

Artigo recebido em 03 de junho de 2021. Aprovado em 06 de julho de 2021. 